vẫn phải nhập ngoại nên chi phí khá cao. Hơn nữa đòi hỏi trình độ cao của phẫu thuật viên nên loại khớp hai khối bằng hai vật liệu trển sử dụng ở các nước phát triển, ít áp dụng ở Việt Nam. Khớp làm bằng vật liệu silicone liền khối hiện tại sản xuất được ở Việt Nam với công nghệ in 3D, chi phí khá rẻ và phương pháp phẫu thuật không quá phức tạp. Hơn nữa sau phẫu thuật bệnh nhân vận động sớm ngay sau mổ, hiệu quả của phẫu thuật gần như tức thì nên thường được ưu tiên sử dụng tại Việt Nam.

Trên thế giới cũng nhiều tác giả thực hiên thay khớp bàn ngón tay bằng silicone và cho kết quả rất khả quan với thời gian theo dõi sau mổ khác nhau: Năm 2018 Tác giả Nathan T morrell và Arnoid peter Weiss công bố thực hiện thay khớp bàn ngón cho 35 bệnh nhân và theo dõi trong 15 năm cho kết quả tốt về lâm sàng 97\% và Xquang là $88 \%$.

Năm 2014 tác giả Bales, Wall và Stern công bố đã tiến hành thay khớp bàn ngón cho 51 bệnh nhân sử dụng khớp silicone theo dõi trong 10 năm thì tỷ lệ tồn tại của khớp silicone là $90 \%$ và bệnh nhân hài lòng với kết quả.

Rettig và Luca báo cáo 12 trong số 13 trường hợp thay khớp bằng silicone đạt hiệu quả tốt đến xuất sắc về khả năng vận động trên tất cả số bệnh nhân với khoảng theo dõi 40 tháng. Khả nằng gấp ngón được cải thiện đáng kể.

\section{KẾT LUÂN}

Với nhiều ưu điểm như phẫu thuật đơn giản, chi phí khá rẻ so với các vật liệu khác, thời gian phục hồi nhanh, hiệu quả giảm đau và phục hồi chức năng sau mổ gân như tức thì. Phương pháp thay khớp bàn ngón tay bằng vật liệu silicone là một lựa chọn rất tốt đối với bệnh nhân chấn thương hoặc bệnh lý như viêm khớp dạng thấp gây mất chức năng khớp bàn ngón hoặc khớp liên đốt ngón tay trong điêu kiện Việt Nam.

\section{TÀI LIÊU THAM KHẢO}

1. J Hand Surg Am. 2018 Mar; 43(3):229-233. doi: 10.1016/j.jhsa.2017.10.010. Epub 2017 Nov 14.

2. J Hand Surg Am. 2014 Mar; 39(3):455-61. doi: 10.1016/j.jhsa.2013.11.008.

3. Acta Orthop Belg. 2014 Jun;80(2):190-5.

4. Hand Clin. 2018 May; 34(2):195-205. doi: 10.1016/j.hcl.2017.12.009. Review.

5. Swanson AB. Silicone rubber implants for replacement of arthritis or destroyed joints in the hand. Surg Clin North Am. 1968; 48:1113-1127.

6. Swanson AB, Maupin BK, Gajjar NV, De Groot Swanson G. Flexible implant arthroplasty in the proximal interphalangeal joint of the hand. J Hand Surg Am. 1985(10):796-805.

7. Orthopade. 2019 May:48(5):378-385. doi: 10.1007/s00132-019-03705-w. Review. German.

8. J Hand Surg Am. 2018 Jun;43(6):574. e1574.e9. doi: 10.1016/j.jhsa.2018.03.008. Epub 2018 Apr 9. Review.

9. J Hand Surg Am. 2014 Jun;39(6):1075-81. doi: 10.1016/j.jhsa.2014.03.033. Epub 2014 May 5.

\title{
MộT SỐ YẾU Tố Có LIÊN QUAN ĐẾN KẾT QUẢ PHỤC HồI CHỨC NĂNG BẰNG PHƯƠNG PHÁP GƯO'NG TRI LIẾU KẾT HợP VỚI VÂ̂N ĐộNG TRI LIỆU Ở BÊ̂NH NHÂN LIỆT NỬA NGƯỜI DO ĐộT QUỴ NÃO
}

\section{Vũ Thị Tâm ${ }^{1}$, Nguyễn Phương Sinh ${ }^{1}$, Nguyễn Vũ Phương ${ }^{2}$, Dương Thu Hồng ${ }^{3}$, Trịnh Minh Phong ${ }^{1}$}

\section{TÓM TẮT}

Mục tiêu: Xác định một số yếu tố có liên quan đến kết quả phuc hồi chức năng bằng phương pháp gương trị liệu kết hợp với vận động trị liệu ở bệnh nhân liệt nửa người do đột quy não. Đối tượng và phương pháp: Nghiên cứu mô tả trên 90 bệnh nhân bị liệt nửa người do đột quy. não được can thiệp bằng

${ }^{1}$ Trường đại học Y Dược Thái Nguyên

²Bệnh viện Trường đại học Y Dược Thái Nguyên

${ }^{2}$ Bệnh viện Y học cổ truyền Cao Bằng

Chịu trách nhiếm chính: Vũ Thị Tâm

Email: bstamphcn@gmail.com

Ngày nhận bài: 23.11.2020

Ngày phản biện khoa học: 30.12.2020

Ngày duyệt bài: 8.01.2021 phương pháp gương trị liệu tại bệnh viện Y học cổ truyền Cao Bằng thời gian từ ngày 3/7/2018 đến ngày 3/7/2020. Kết quả và kết luận: Ớ nhóm tuổi 60 trở xuống có tỷ lệ vận động tốt là $92,31 \%$ cao hơn rất nhiêuu so với nhóm trên 60 tuổi là $20 \%(p<0,05)$. Bệnh nhân có thời gian đến viện sớm dưới 1 tháng hoặc từ 1 đến 3 tháng sau khi đột quy có tỷ lệ vận động tốt lần lượt là $96,43 \%$ và $86,21 \%$ cao hớn nhiêu so với bênh nhân đến muộn sau 3 tháng là 39,39\% $(p<0,05)$. Bệnh nhân có về khiếm khuyết thần kinh theo thang điểm NIHSS ở mức độ nhe thì kết quả phục hồi chức năng đạt mức độ tốt chiểm tỉ lệ $100 \%$ $(p<0,05)$. Các yếu tố giới, bên liẹt, loai tổn thương não không có mối liên quan đến kết quả phục hồi chức năng.

Tư khóa: Đột quỵ não, phục hồi chức năng, vật lý trị liệu, nhồi máu não, vận động trị liệu, gương trị liệu. 


\section{SUMMARY}

\section{THE ASSOCIATED FACTORS OF REHABILITATION OUTCOMES WITH COMBINATION OF MIRROR THERAPY AND PHYSICAL THERAPY IN PATIENTS WITH HEMIPARESIS DUE TO STROKE}

Objective: To determine the associated factors of rehabilitation outcomes with combination of mirror therapy and physical therapy in patients with hemiparesis due to stroke. Subjects and methods: observation study with 90 patients with hemiparesis due to stroke. They are treated by mirror therapy in Cao Bang hospital of traditional medicine in the period from July, 3rd 2018 to July, $3^{\text {rd }} 2020$. Results and conclusions: The proportion of excellent movement ability in the under 60 years old group is $92,31 \%$, which is higher than in the above 60 years old group, at $20 \%$ $(p<0,05)$. The proportion of excellent movement ability in patients who was hospitalized within a month group and from one to three months group are $96,43 \%$ and $86,21 \%$, respectively; these figures are higher significantly than in more- than-3- month-group, at $39,39 \%(p<0,05)$. Patients, with minor neurological defects according to NIHSS score, have good rehabilitation result, at $100 \%(p<0.05)$. The factors comprise: gender, paralysis, and type of brain damage were not associated with rehabilitation outcomes.

Keywords: stroke, rehabilitation, ischemic stroke, physical therapy, mirror therapy.

\section{I. ĐĂT VẤN ĐỀ}

Đôt quy não đứng hàng đầu trong các nguyên nhân quan trọng nhất của tàn phế ở người lớn. Liệt nửa người là biểu hiện thường găp nhất của đột quy não. Theo phân loại của Tổ chức $Y$ tế Thế giới (WHO), người bênh liệt nửa người do đột quy não thuộc loại đa tàn tật; $2 / 3$ những người bệnh này cần phục hồi chức năng để làm giảm tối đa các di chúng và sớm đưa người tàn tật trở lại với cuộc sống độc lập của họ.Tổ chức y tế thể giới đã đưa ra kết luận: Đột quy não là bênh dự phòng có kêt quả; nễu điều trị sớm có thể hạ chế tử vong và di chứng Tại Việt Nam, vai trò của phục hồi chức năng cũng như các yếu tố liên quan kết quả điều trị phục hồi chức năng ở người bệnh liệt nửa người do đột quy não vẫn còn hiếm tác giả đề cập đến. Phương pháp gương trị liệu là phương pháp tâp luyện phục hồi chức năng vận động cho nửa người bên liệt. Phương pháp tập đơn giản dễ thực hiện và mang lại hiệu quả điều trị cho bệnh nhân. Đặc biệt, rất phù hợp với điều kiện kinh tế và tâm lý điêu trị của người dân tại tỉnh Cao Bằng. Để nâng cao hiệu quả của phương pháp, đồng thời tìm ra một số yếu tố liên quan đến kết quả tập luyện, chúng tôi tiến hành nghiên cứu này với mục tiêu: Xác định một số yếu tố có liên quan đến kết quả phục hồi chức năng bằng phương pháp gương trị liệu kết hợp với vận động trị liệu ở bệnh nhân liệt nửa người do đột quy não.

\section{II. ĐỐI TƯỢNG VÀ PHƯƠNG PHÁP NGHIÊN CỨU}

2.1. Đối tượng nghiên cứu. Gồm 90 bênh nhân liệt nửa người do đột quy não đang được điều trị tại bệnh viện $Y$ học cồ truyền $C a o$ Bằng với các tiêu chuẩn chọn bệnh nhân như sau: Bệnh nhân liệt nửa người do đột quỵ não lần đầu tiển. Bệnh nhân có thể giao tiếp được. Bệnh nhân không bị rối loạn nhận thức. Bệnh nhân ngồi được và có giảm chức năng của chi trên bên liệt nhưng nâng được vai và duỗi được cổ tay.

\section{Tiêu chuẩn loại trừ:}

- Bệnh nhân có các bệnh lý nội khoa nặng như: Suy tim nặng, suy thận.

- Mắc các bệnh khác ảnh hưởng đến chức năng vận động trước khi bị đột quy. não như: Bệnh Gout, dị tật, viêm khớp cổ tay, bàn ngón tay, hoặc chấn thương khớp cổ tay, bàn ngón tay.

\section{- Bênh nhân động kinh.}

\subsection{Phương pháp nghiên cứu}

* Phương pháp nghiên cứu mô tả.

* Chọn mẫu ngẫu nhiên thuận tiện.

* Chỉ tiêu nghiên cứu:

- Tuổi, giới, thời gian bị bệnh.

- Loại tổn thương não.

- Khiếm khuyết thần kinh theo thang điểm NIHSS.

\subsection{Quy trình điều trị}

- Điều trị bằng hồng ngoại 30 phút/ngày.

- Vận động trị liệu 30 phút/ngày.

- Điện xung trị liệu 10 phút/ngày dòng xung Faradic.

- Điều trị bằng gương trị liệu trong thời gian 30 phút/ngày, 5 ngày/tuần. Nguyên tắc sử dụng gương là tay lành của bệnh nhân sẽ được đặt đối diện với gương. Tay liệt đặt phía đằng sau gương. Trong suốt thời gian tập, bệnh nhân sẽ quan sát cử động của tay lành qua gương, cố gắng tưởng tượng tay cử động trong gương chính là tay liệt. Đồng thời, cử động tay liệt theo tay lành.

+ Các bài tập cho bàn tay và cổ tay với gương như sau: Gập duỗi, dang khép các ngón tay, đối chiếu ngón cái với các ngón tay khác, gập duỗi cổ tay, nghiêng trụ, nghiêng quay cổ tay. Tập dụng cụ làm tăng sức mạnh bàn tay như bóng cao su hoặc miếng mút.

+ Các bài tập cho chân với gương như sau: Tập gấp, duỗi, dạng, khép, xoay trong, xoay ngoài khớp háng; gấp, duô̂i khớp gối. Tập gấp mặt lòng, gấp mặt mu, nghiêng vào trong và nghiêng ra ngoài khớp cổ chân. Tập gấp, duỗi, 
dạng, khép ngón chân.

- Đánh giá kết quả sau 3 tháng can thiệp.

\subsection{Nội dung đánh giá}

- Liên quan giữa tuối và kết quả phục hồi chức năng.

- Liên quan giữa giới và kết quả phục hồi chức năng sau 3 tháng điều trị.

- Liên quan giữa bên liệt và kết quả phục hồi chức năng sau 3 tháng điều trị.

- Liên quan giữa loại tổn thương não và kết quả phục hồi chức năng.
- Liên quan giữa thời gian bị bệnh và kết quả phục hồi chức năng.

- Liên quan giữa khiếm khuyết thần kinh và kết quả phục hồi chức năng

2.5. Xử lý và phân tích số liêu. Các số liệu được xử lý bằng phương pháp toán thống kê $y$ học sử dụng phần mềm SPSS 16.0.

2.6. Đạo đức trong nghiên cứu. Nghiên cứu được sự đồng ý của các khoa nghiên cứu và bệnh viện. Tất cả bệnh nhân tự nguyện tham gia và có quyền rút ra khỏi nghiên cứu bất cứ lúc nào.

\section{KẾT QUẢ VÀ BÀN LUÂN}

Bảng 3.1. Liên quan giữa tuổi và kêt quả phục hồi chức năng sau điều trị

\begin{tabular}{|c|c|c|c|c|c|c|c|}
\hline \multirow{2}{*}{ Mức độ } & \multicolumn{2}{|c|}{$\leq 60$} & \multicolumn{2}{|c|}{$>60$} & \multicolumn{2}{|c|}{ Tống } & \multirow{2}{*}{ p } \\
\hline & $\mathbf{n}$ & $\%$ & $\mathbf{n}$ & $\%$ & $\mathbf{n}$ & $\%$ & \\
\hline Tốt & 60 & 92,31 & 5 & 20 & 65 & 72 & \multirow{4}{*}{$<0,05$} \\
\hline Khá & 5 & 7,69 & 15 & 60 & 20 & 22,22 & \\
\hline Trung bình & 0 & 0 & 4 & 16 & 4 & 4,44 & \\
\hline Kém & 0 & 0 & 1 & 4 & 1 & 1 & \\
\hline Tống & 65 & 100 & 25 & 100 & 90 & 100 & \\
\hline
\end{tabular}

Nhận xét: Ớ nhóm tuối 60 trở xuống có tỷ lệ vận động tốt là 92,31\% cao hơn rất nhiều so với nhóm trên 60 tuổi là $20 \%$. Sự khác biệt có ý nghĩa thống kê p<0,05.

Bảng 3.2. Liên quan giứa giới và kêt quả phục hồi chức năng sau điều trị

\begin{tabular}{|c|c|c|c|c|c|c|c|}
\hline \multirow{2}{*}{ Mức độ } & \multicolumn{2}{|c|}{ Nam } & \multicolumn{2}{|c|}{ Nữ } & \multicolumn{2}{|c|}{ Tống } & \multirow{2}{*}{ P } \\
\cline { 2 - 7 } & $\mathbf{n}$ & $\mathbf{\%}$ & $\mathbf{n}$ & $\mathbf{\%}$ & $\mathbf{n}$ & $\mathbf{\%}$ & \\
\hline Tốt & 47 & 73,44 & 18 & 69,23 & 65 & 72,22 & \\
\hline Khá́ & 14 & 21,88 & 6 & 23,08 & 20 & 22,22 & \\
\hline Trung binh & 3 & 4,69 & 1 & 3,85 & 4 & 4,44 & $<0,05$ \\
\hline Kém & 0 & 0 & 1 & 3,85 & 1 & 1,11 & \\
\hline Tống & $\mathbf{6 4}$ & $\mathbf{1 0 0}$ & $\mathbf{2 6}$ & $\mathbf{1 0 0}$ & $\mathbf{9 0}$ & $\mathbf{1 0 0}$ & \\
\hline
\end{tabular}

Nhận xét: Tỷ lệ vận động mức độ tốt ở nam giới là 73,44\% điều trị cao hơn so với nữ giới là $69,23 \%$. Tuy nhiên sự khác biệt không có ý nghĩa thống kê p>0,05.

Bảng 3.3. Liên quan giứa bên liệt và kêt quả phục hồi chức năng sau điều trị

\begin{tabular}{|c|c|c|c|c|c|c|c|}
\hline \multirow{2}{*}{ Mức độ } & \multicolumn{2}{|c|}{ Trái } & \multicolumn{2}{|c|}{ Phải } & \multicolumn{2}{|c|}{ Tống } & P \\
\cline { 2 - 8 } & $\mathbf{n}$ & $\mathbf{\%}$ & $\mathbf{n}$ & $\mathbf{\%}$ & $\mathbf{n}$ & $\mathbf{\%}$ & \\
\hline Tốt & 37 & 80,43 & 35 & 79,55 & 72 & 80 & \\
\hline Khá & 7 & 15,22 & 8 & 18,18 & 15 & 16,67 & \multirow{2}{*}{$>0,05$} \\
\hline Trung bình & 2 & 4,35 & 1 & 2,27 & 3 & 3,33 & \\
\hline Kém & 0 & 0 & 0 & 0 & 0 & 0 & \\
\hline Tống & $\mathbf{4 6}$ & $\mathbf{1 0 0}$ & $\mathbf{4 4}$ & $\mathbf{1 0 0}$ & $\mathbf{9 0}$ & $\mathbf{1 0 0}$ & \\
\hline
\end{tabular}

Nhận xét: Không có mối liên quan giữa bên liệt với mức độ vận động sau 03 tháng điều trị $p>0,05$.

Bảng 3.4. Liên quan giữa loại tổn thương não và và kểt quả phục hối chức năng sau điều trị

\begin{tabular}{|c|c|c|c|c|c|c|c|}
\hline \multirow{2}{*}{ Mức độ } & \multicolumn{2}{|c|}{ Nhối máu não } & \multicolumn{2}{|c|}{ Xuất huyết não } & \multicolumn{2}{|c|}{ Tống } & \multirow{2}{*}{ p } \\
\cline { 2 - 7 } & $\mathbf{n}$ & $\mathbf{\%}$ & $\mathbf{n}$ & $\mathbf{\%}$ & $\mathbf{n}$ & $\mathbf{\%}$ & \\
\hline Tốt & 56 & 83,58 & 16 & 69,57 & 72 & 80 & \\
\hline Khá & 11 & 16,42 & 4 & 17,39 & 15 & 16,67 & \multirow{2}{*}{$>0,05$} \\
\hline Trung bình & 0 & 0 & 3 & 13,04 & 3 & 3,33 & \\
\hline Kém & 0 & 0 & 0 & 0 & 0 & 0 & \\
\hline Tống & $\mathbf{6 7}$ & $\mathbf{1 0 0}$ & $\mathbf{2 3}$ & $\mathbf{1 0 0}$ & $\mathbf{9 0}$ & $\mathbf{1 0 0}$ & \\
\hline
\end{tabular}

Nhận xét: Nhóm bệnh nhân liệt nửa người do nhồi máu não đạt kết quả điều trị tốt là 70,15\%. Nhóm bệnh nhân liệt nửa người do chảy máu não đạt kết quả điều trị tốt là 78,26 . Kết quả phục hồi chức năng của các nguyên nhân này không có sự khác biệt đáng kể, không có ý nghĩa thống kê với p>0,05. 
Bảng 3.5. Liên quan giữa thời gian bị bệnh và và kêt quả phục hồi chức năng sau 3 tháng điều trị

\begin{tabular}{|c|c|c|c|c|c|c|c|c|c|}
\hline \multirow{2}{*}{ Mức độ } & \multicolumn{2}{|c|}{ Dưới 4 tuân } & \multicolumn{2}{|c|}{$\mathbf{4 - 1 2}$ tuân } & \multicolumn{2}{|c|}{ Trên 12 tuần } & \multicolumn{2}{|c|}{ Tống } & p \\
\cline { 2 - 10 } & $\mathbf{n}$ & $\mathbf{\%}$ & $\mathbf{n}$ & $\mathbf{\%}$ & $\mathbf{n}$ & $\mathbf{\%}$ & $\mathbf{n}$ & $\mathbf{\%}$ & \\
\hline Tốt & 27 & 96,43 & 25 & 86,21 & 13 & 39,39 & 65 & 72,22 \\
\hline Khá & 1 & 3,57 & 3 & 10,34 & 16 & 48,48 & 20 & 22,22 \\
\hline Trung bình & 0 & 0 & 1 & 3,45 & 3 & 9,09 & 4 & 4,44 & \multirow{2}{*}{$<0,05$} \\
\hline Kém & 0 & 0 & 0 & 0 & 1 & 3,03 & 1 & 1,11 & \\
\hline Tống & $\mathbf{2 8}$ & $\mathbf{1 0 0}$ & $\mathbf{2 9}$ & $\mathbf{1 0 0}$ & $\mathbf{3 3}$ & $\mathbf{1 0 0}$ & $\mathbf{9 0}$ & $\mathbf{1 0 0}$ & \\
\hline
\end{tabular}

Nhân xét: Thời gian bắt đầu vào viên sau khi bi tai biến có mối liên quan chă̆t chẽ với kết quả phục hồi chức năng của nhóm can thiệp: những bệnh nhân có thời gian đến viện sớm dưới 1 tháng hoắc từ 1 đến 3 tháng sau khi đột quỵ có tỷ lệ vận động tốt lần lượt là $96,43 \%$ và $86,21 \%$ và sự khác biệt có ý nghĩa thống kê với $p<0,05$.

Bảng 3.6. Liên quan giữa khiếm khuyết thân kinh theo thang điểm NIHSS và kêt quả phục hồi chức năng sau 3 tháng điều trị

\begin{tabular}{|c|c|c|c|c|c|c|c|c|c|}
\hline \multirow{2}{*}{ Mức độ } & \multicolumn{2}{|c|}{ Nă̆ng } & \multicolumn{2}{c|}{ Trung bình } & \multicolumn{2}{c|}{ Nhê } & \multicolumn{2}{|c|}{ Tống } & p \\
\cline { 2 - 10 } & $\mathbf{n}$ & $\mathbf{\%}$ & $\mathbf{n}$ & $\mathbf{\%}$ & $\mathbf{n}$ & $\mathbf{\%}$ & $\mathbf{n}$ & $\mathbf{\%}$ & \\
\hline Tốt & 0 & 0 & 22 & 63 & 50 & 100 & 72 & 80 \\
\hline Khá & 4 & 80 & 11 & 31 & 0 & 0 & 15 & 16,67 & \\
\hline Trung bình & 1 & 20 & 2 & 6 & 0 & 0 & 3 & 3,33 & $<0,05$ \\
\hline Kém & 0 & 0 & 0 & 0 & 0 & 0 & 0 & 0 & \\
\hline Tống & $\mathbf{5}$ & $\mathbf{1 0 0}$ & $\mathbf{3 5}$ & $\mathbf{1 0 0}$ & $\mathbf{5 0}$ & $\mathbf{1 0 0}$ & $\mathbf{9 0}$ & $\mathbf{1 0 0}$ & \\
\hline
\end{tabular}

Nhận xét: Bệnh nhân có mức đô khiếm khuyết thần kinh ở mức độ nhẹ thì kết quả phục hồi chức năng ở mức độ tốt chiếm $100 \%$, khiếm khuyết thần kinh ở mức độ nặng thì kết quả phục hồi chức năng kém và sự khác biệt có ý nghĩa thống kê với $p<0,05$.

\section{BÀN LUẬN}

4.1. Liên quan giữa tuổi và kết quả phục hồi chức năng. Kết quả nghiên cứu của chúng tôi cho thấy, ở nhóm tuổi từ 60 tuổi trở xuống có kết quả phục hồi tốt hơn so với nhóm trên 60 tuổi. Kết quả này cũng phù hợp với kết quả nghiên cứu của các tác giả khác, đó là tuổi càng cao thì khả năng phục hồi càng khó, trong nghiên cứu của chúng tôi có những cụ 78 tuổi [6]; Với những bệnh nhân cao tuổi, khả năng tâp trung có thể kém hơn những bệnh nhân trẻ tuổi, áp lực tâm lý tuổi già, vị trí nghỉ ngơi tại viện không được thoải mái như tại gia đình, đó có thể là nguyên nhân làm cho hiệu quả phục hồi bàn tay không đạt được ở mức cao nhất. Ngoài ra thì nhiều nghiên cứu cũng đã chứng minh tuổi càng cao thì mức độ hồi phục càng chậm, đặc biệt là mức khéo léo của bàn tay. Nhìn chung, tuổi càng cao mức vận động bàn tay càng giảm, càng khó điều trị và phục hồi điều này cũng phù hợp với đặc điểm sinh lý của tuổi già [1]. Với nhận thức đó nên một số chuyên gia phục hồi chức năng đã đề xuất chiến lược phục hồi đối với người trẻ tuổi là tập luyện để phục hồi lại những chức năng đã giảm hoặc đã mất. Còn đối với người cao tuổi là ưu tiên chiến lược phục hồi bù trừ hoặc thay thế, để giúp bệnh nhân vẫn có thể tự chăm sóc bản thân và độc lập tối đa các hoạt động chức năng trong sinh hoạt hàng ngày, măcc dù không thể bình thường hoá được nửa người bên liệt và thực tế bình thường hoá không phải là mục tiêu chính của phục hồi chức năng.

4.2. Liên quan giữa giới và kết quả phục hồi chức năng. Kết quả nghiên cứu của chúng tôi cho thấy tỳ lệ vận động mức độ tốt ở nam giới là $73,44 \%$ cao hơn so với nữ giới là $69,23 \%$. Tuy nhiên sự khác biệt không có ý nghĩa thống kê $(p>0,05)$. Kết quả nghiên cứu này cũng tương tự với kết quả nghiên cứu của tác giả Nguyễn Thị Kim Liên năm 2012, không có sự khác biệt có ý nghĩa thống kê về trung bình mức độ vận động bàn tay cũng như mức khéo léo trung bình ở 2 giới. Như vậy, có thể nói kết quả phục hồi chức năng phụ thuộc vào chính ý thức tự giác tự tập luyện và ý chí của người bệnh chứ không liển quan đến giới tính.

4.3. Liên quan giữa bên liệt và kết quả phục hồi chức năng. Kết quả nghiên cứu của chúng tôi còn còn cho thây không có sự khác biệt bên liệt đến sự hồi phục về mức độ vận động sự khác biệt trên chưa có ý nghĩa thống kê với $p>0,05$. Kết quả phục hồi chức năng của bệnh nhân liệt nửa người bên phải và bệnh nhân liệt nửa người bên trái đã được nhiều chuyên gia phục hồi chức năng nghiên cứu và cho nhiêu đánh giá kết quả khác nhau. 
Kết quả nghiên cứu này cũng tương tư với kết quả nghiên cứu của tác giả Nguyễn Thị Kim Liên năm 2012, không có sự khác biệt có ý nghĩa thống kê về trung bình mức độ vận động bàn tay cũng như mức khéo léo trung bình ở 2 giới. Tương tự như vậy tác giả cũng chưa thấy có mỗi liên quan giữa chức năng vận động bàn tay cả về vận động và khéo léo với bên liệt với p>0,05.

Tuy nhiên theo Bruce $\mathrm{H}$ (2005) lại cho rằng, mất vận động chi trên có mối liên quan đến tổn thương bán câuu não trái [7]. Nghĩa là, những bênh nhân liệt bên phải có nguy cơ bi mất vận động chi trên hơn những bệnh nhân liệt bên trái. Một số tác giả khác lại cho rằng bệnh nhân đặc biệt nửa người bên trái có nhiêu rối loạn trầm trọng hơn so với bệnh nhân liệt nửa người bên phải. Về cơ bản kết quả phục hồi vận động chung của hai nhóm bệnh nhân không khác nhau nhưng khả năng phục hồi về tự chăm sóc bản thân trong sinh hoạt hàng ngày ở bệnh nhân liêt nửa người trái kém hơn so với bệnh nhân liệt nửa người bên phải.

4.4. Liên quan giữa loại tổn thương não và và kết quả phục hồi chức năng. Khả năng phục hồi vận động của bệnh nhân liệt nửa người do đột quỵ não không phụ thuộc vào nguyên nhân do chảy máu não hay nhồi máu não hay nguyên nhân nào khác. Sự khác biệt không có ý nghĩa thống kê. Kết quả tại bảng 3.4 của chúng tôi nghiên cứu được cho thấy trùng lặp với nhiều kết quả của các tác giả đã nghiên cứu.

Theo Trần Văn Chương và Nguyễn Xuân Nghiên, "Bước đầu nghiên cứu một số yếu tố tiên lượng phục hồi vận động của bệnh nhân liệt nửa người do đột quy. não" cho thây kết quả điều trị đạt $76,5 \%$ do nguyên nhân chảy máu não, kết quả điều trị đạt $81 \%$ do nguyên nhân nhồi máu não.

4.5. Liên quan giữa thời gian bị bệnh và và kết quả phục hồi chức năng. Kết quả nghiên cứu cho thấy thời gian bắt đầu vào viện sau khi bị tai biến có mối liên quan chặt chẽ với kết quả phục hồi chức năng của nhóm can thiệp: những bệnh nhân có thời gian đến viện sớm dưới 1 tháng hoặc từ 1 đến 3 tháng sau khi đột quy có tỷ lệ vận động tốt lần lượt là $96,43 \%$ và $86,21 \%$ cao hợn nhiêu so với bệnh nhân đến muộn sau 3 tháng là 39,39\% và sự khác biệt có ý nghĩa thống kê với $p<0,05$.

Tổ chức $Y$ tế thế giới đã có khuyến cao là ngay từ những ngày đâu tiên sau đột quy,, kể cả khi bệnh nhân vấn còn hôn mê thì việc phòng chống co cứng, biến dạng co rút và các thương tật thứ cấp khác sau này cũng phải được coi trọng như là phòng chống loét và các biến chứng khác trong giai đoạn cấp. Kỹ thật chính được áp dụng trong giai đoạn này là kỹ thuật vị thế. Ngay từ những ngày đẩu tiên, bệnh nhân được đặt nằm ở các tư thế đúng theo mẫu phục hồi, các vị thế nằm đó được thay đổi thường xuyên từ 2 - 3 giờ/lần. Kỹ thuật vị thế đúng kết hợp với tập vận động thụ động thường xuyên nữa người bên liệt mỗi ngày từ 2-3lần, sau đó tuỳ theo các giai đoạn tiến triển của bệnh nhân mà ứng dụng các kỹ thuật tập luyện vận động phù hợp [4].

Theo Goldie, những bệnh nhân phục hồ chức năng sớm trong những tháng đâu sau đột quy. não sẽ có kết quả tốt hơn bệnh nhân phục hồi chức năng muộn. Kết quả nghiên cứu của tác giả cũng cho thây kết quả phục hồi của bệnh nhân liệt nửa người do đột quy não phụ thuộc vào thời gian bệnh nhân bắt đầu được luyện tập phục hồi chức năng sau tai biến. Thời gian càng sớm kết quả phục hồi càng tốt, bệnh nhân được điều trị trước 6 tuần đạt kết quả tốt và trung bình là 85,0\%; bệnh nhân điêuu trị trước 12 tuần đạt kết quả tốt và̀ trung bình là $72,7 \%$; bệnh nhân điều trị sau 12 tuần đạt kết quả tốt và trung bình là $54,5 \%$ [2].

4.6. Liên quan giữa khiếm khuyết thân kinh theo thang điểm NIHSS và kết quả phục hồi chức năng. Kết quả bảng 3.6 cho thấy bệnh nhân có mức đô khiếm khuyết thần kinh ở mức độ nhẹ thì kết quả phục hồi chức năng ở mức độ tốt chiếm 100\%, khiếm khuyết thân kinh ở mức độ nặng thì kết quả phục hồi chức năng kém và sự khác biệt có ý nghĩa thống kê với $p<0,05$.

Đánh giá khiếm khuyết thần kinh theo thang điểm NIHSS [5] là thang điểm đánh giá về ý thức, khả năng nhìn, ngôn ngữ, khả năng thăng bằng, điều vận động tác. Trong nghiên cứu của chúng tôi, việc can thiệp bằng phương pháp gương trị liệu đòi hỏi não phải hoạt động trong quá trình tập luyện, vì vậy trong tiêu chuẩn loại trừ bệnh nhân chúng tôi đã loại trừ những bệnh nhân có rối loạn ý thức nặng. Đồng thời việc can thiệp bằng phương pháp gương ưu việt hớn các phương pháp tập luyện khác khi có vai trò của việc kích thích sự tưởng tưởng vận động của não đã làm cho việc hồi phục các khiếm khuyết thần kinh cải thiện rõ rệt. Như vậy với các trường hợp khiếm khuyết thần kinh mức độ nhẹ thì kết quả phục hồi tốt.

\section{KẾT LUÂN}

- Ở nhóm tuổi 60 trở xuống có tỷ lệ vận động tốt là $92,31 \%$ cao hơn rất nhiều so với nhóm 
trên 60 tuổi là 20\%. Sự khác biệt có ý nghĩa thống kê $p<0,05$.

- Bệnh nhân có thời gian đến viện sớm dưới 1 tháng hoặc từ 1 đến 3 tháng sau khi đột quy có tỷ lệ vận động tốt lần lượt là $96,43 \%$ và $86,21 \%$ và sự khác biệt có ý nghĩa thống kê với $p<0,05$.

- Bênh nhẩn có về khiếm khuyết thần kinh theo thang điểm NIHSS ở mức đô nhe thì kết quả phuc hồi chức năng đạt mức độ tốt chiếm tỉ lệ 100\%. Sự khác biêt có ý nghĩa thống kê với $p<0,05$.

- Các yếu tố giới, bên liệt, loại tổn thương não không có mối liên quan đến kết quả phục hồi chức năng.

\section{TÀI LIÊU THAM KHẢO}

1. Nguyễn Thị Kim Liên (2011), Nghiên cứu phục hồi chức năng bàn tay trên bênh nhân liệt nửa người do đột quy não. Luận văn tiến sỹ Y học, Trường Đại học Y Hà Nội, tr. 90 - 95.
2. Trân Mỹ Luât (2008), Đánh giá kết quả phục hồi chức năng vẩn động cúa bệnh nhân tai biến mạch máu não tai bênh viên điều dưỡng - phuc hồi chức năng tỉnh Thái Nguyên. Luâan văn thạc sỹ Đại học Y Dược Thái Nguyên, tr 78-79.

3. Nguyển Xuân Nghiên, Trân Văn Chương (1998), Bước đầu nghiên cứu một số yếu tố tiên lượng Phuc hồi vân đông của bênh nhân liêt nưa người do tai biến mạch máu não, kỷ yếu công trình nghiên cứu khoa học, Hội phục hồi chức năng Việt Nam, nhà xuất bản $Y$ hoc, (5), tr.65-75.

4. Davis J.Z (1985), The Bobath approach to the treatment of adult hemiplegia, Occupational therapy. The C.V. Mosby Company. pp 217 - 226.

5. Jauch E.C (2013), Guidelines for the Early Management of Patients With Acute Ischemic Stroke, Stroke, American Stroke Association, 44, pp. 870-947

6. Petrea RE, Beiser AS (2009), Gender diffirences in stroke indidence and postroke disability in the Framingham Heart study stroke, p $102-105$.

7. Bruce H, Dobkin MD (2005), Rehabilitation after stroke, N Engl J Med, 352: p 1677-1684

\section{NHU CẦU SỬ DƯNG ỨNG DƯNG THIẾT BI DI ĐộNG HỖ TRỢ QUẢN LÝ BẾNH TRÀO NGƯỢC DA DÀY THỰC QUẢN}

\section{TÓM TẮT}

Tại Việt Nam, hiện chưa có ứng dụng di động (ƯDDĐ) về bênh lý trào ngước da dày - thực quản (GERD) được phát triển. Nghiên cứu được thực hiện trên bệnh nhân GERD khám tại Bệnh viện Đại học Y Hà Nội và Viện nghiên cứu và đào tạo tiêu hóa gan mậtnhằm mô tả trải nghiệm khi tìm kiếm thông tin về bệnh và nhu cầu sử dụng ƯDDĐ trong quản lý bệnh GERD từ tháng 04/2020 đến tháng 6/2020. Trong 485 bệnh nhân thu tuyển, $56,5 \%$ từng tìm hiểu về GERD, tỷ lệ cao hơnở đối tượng có trình độ học vấn trên cấp 3 và ở thành thi. 49,1\% bệnh nhân có nhu cầu sử dụngƯDDĐ, tỷ lề cao hơn ở đối tượng ở thành thị ( $\mathrm{OR}=1,45 ; 95 \% \mathrm{CI}: 1,01-2,09)$, trình đô họ vấn trên cấp $3(\mathrm{OR}=1,66 ; 95 \% \mathrm{CI}: 1,06-2,61)$, điểm $\mathrm{GERDQ} \geq 8$ $(\mathrm{OR}=1,60 ; 95 \% \mathrm{CI}: 1,10-2,32)$. Đa số bênh nhân đề xuất các nội dung cho ƯDDĐ:chế độ ăn uống, sinh hoat, tương tác bác sỹ, kiến thức vể bênh. Kết quả khảo sát cho thấy nhu cầu sử dụng ƯDDĐ cao ở các bệnh nhân, đồng thời đưa ra gợi ý các tính năng cần thiết để phát triển U'DDĐ.

Tư khoá: ứng dụng di động, trào ngược dạ dày thực quản (GERD), thông tin y tế.

\footnotetext{
${ }^{1}$ Trường Đại học Y Hà Nọi

${ }^{2}$ Viện nghiên cứu và đào tạo tiêu hoá, gan mật

Chịu trách nhiệm chính: Đào Việt Hằng

Email: hangdao.fsh@gmail.com

Ngày nhận bài: 20.11.2020

Ngày phản biên khoa hoc: 18.12.2020

Ngày duyệt bài: 7.01.2021
}

Đào Việt Hằng ${ }^{1,2}$, Trần Thị Ngọc Ánh², Nguyễn Mạnh Hùng ${ }^{2}$, Nguyễn Mạnh Duy ${ }^{2}$

\section{SUMMARY}

\section{THE DEMAND FOR USING MOBILE} APPLICATIONS TO MANAGE

\section{GASTROESOPHAGEAL REFLUX DISEASE}

In Vietnam, mobile applications with acceptable contents about gastroesophageal reflux disease (GERD) have not been developed. This survey aimed to describe the patient's experience in searching for GERD information and the demand for GERD mobile application. The survey was conducted in all patients having typical GERD symptoms who visited Hoang Long Clinic and Hanoi Medical University Hospital from April to June, 2020. Among 485 study participants, $56,5 \%$ have ever searched about GERD information, significantly higher among patients having higher education levels than high school and living in urban areas. $234 / 477$ patients $(49,1 \%)$ demonstrated a need for GERD app, which was higher among patients living in urban area (OR = 1,45; 95\% CI: 1,01-2,09), having the educational level of high school and higher (OR = $1,66 ; 95 \% \mathrm{CI}: 1,06-2,61)$, GERDQ score $\geq 8$ (OR = 1,60; 95\% CI: 1,10- 2,32). Most of patients recommended the contents for app development regarding dietary guidelines, daily activities, doctor interactions, and relevant information about GERD. The findings of our survey not only showed that the demands for GERD app usage are high among patients but also proposed some essential features for GERD app development.

Keywords: mobile application, gastroesophageal reflux disease (GERD), health information. 